\title{
INFLUENCE OF THERMOCYCLING FOLLOWING APPLICATION OF FLUORIDE-RELEASING RESIN ON SHEAR BOND STRENGTH OF METAL BRACKETS
}

\author{
Nabawy A Alrobeigy*
}

\begin{abstract}
Objectives: To assess the influence of thermocycling following application of fluoride resin agent on shear bond strength (SBS) of metal orthodontic brackets bonded with two self-etching primers (SEPs).

Materials and methods: Eighty extracted upper premolars were randomly divided into 4 equal groups $(\mathrm{n}=20)$ and stainless steel brackets were bonded to their buccal surfaces as follows: group 1, teeth were conditioned with Transbond Plus SEP (3M Unitek, Monrovia, Calif), then brackets were bonded with Transbond XT adhesive (3M Unitek) and no fluoride resin applied; group 2, teeth were bonded as in group 1, and subsequently a fluoride-releasing resin (Ortho-Coat, Pulpdent, Watertown, Mass) was applied ; group 3 teeth were conditioned with Clearfil Protect Bond antimicrobial SEP (Kuraray Medical, Osaka, Japan), then brackets were bonded with Transbond XT adhesive and no fluoride resin applied; and in group 4, the same protocol for brackets bonding as in group 3 was used followed by an application of Ortho-Coat. All specimens were stored in distilled water $\left(24 \mathrm{~h} ., 37^{\circ} \mathrm{C}\right)$ then, half of each group $(\mathrm{n}=10)$ subjected to SBS debonding and the other half $(\mathrm{n}=10)$ were thermocycled before debonding. The adhesive remnant index (ARI) score was also recorded after debonding. The data of SBS and ARI scores were statistically analyzed by using 3-way ANOVA and Chi-Square test, respectively
\end{abstract}

Results: The application of Ortho-Coat had no significant effect on SBS values of both SEPs, either before or after thermocycling. SBS values of both SEPs were not significantly changed by thermocycling whether Ortho-Coat was applied or not. No significant difference was noted between the two SEPs in any application condition. No significant differences were found in the ARI scores.

Conclusions: The application of fluoride-releasing resin had no negative effect on SBS of metal brackets bonded with the two SEP systems. Thermocycling had no effect on SBS of the both SEPs either with or without fluoride-releasing resin application.

KEYWORDS: Orthodontic brackets, bond strength, fluoride-releasing resin, self-etching primers, thermocycling.

* Assistant Professor, Department of Dental Biomaterials, Faculty of Dentistry, Tanta University, Egypt. 


\section{INTRODUCTION}

The reliable bonding of orthodontic brackets to tooth enamel surfaces is an essential step in clinical treatment; nonetheless, it is interim, since the brackets should be removed after active treatment, and leaving a sound unchanged enamel surface is the primary aim of the clinicians after brackets debonding. ${ }^{1,2}$ The traditional method for bonding metal brackets to tooth surface require etching of the enamel surface with phosphoric acid. ${ }^{3}$ However, phosphoric acid etching has been stated to causes greater damage of enamel surface. ${ }^{4-7}$ Self-etching primers (SEPs), which combine etching and priming in a single component, were introduced and they displayed many advantages such as simplification of bonding procedures, saving chair-time, and decreasing technique sensitivity. ${ }^{6,8}$ Moreover, the more conservative etching capacity of SEPs due to their higher $\mathrm{pH}$ in comparison to phosphoric acid, has been proposed to reduce the iatrogenic damage to the enamel. ${ }^{2,10}$ Regardless of the gentle etch pattern produced by SEPs, an adequate SBS of brackets has been established in many studies and their use in bonding orthodontic brackets has increased significantly. ${ }^{11-13}$

However, enamel demineralization around orthodontic brackets still remains a challenge. ${ }^{14}$ The formation of undesirable white spot lesions during orthodontic treatment still occur due to the decrease of $\mathrm{pH}$ and the increase of bacterial growth in dental plaque around the brackets, as well as the increased sites of food retention. ${ }^{15,16}$

Various methods have been proposed in the literature to inhibit enamel decalcification associated with orthodontic bonded brackets, such as fluoridecontaining toothpastes and mouth washes, ${ }^{17}$ fluoride varnishes, ${ }^{18,19}$ chlorhexidine varnish, polymeric coating ${ }^{20}$ resin veneer coating, ${ }^{21}$ fluoride-releasing elastomeric modules and chains, ${ }^{22}$ or fluoridereleasing bonding agents. ${ }^{17}$ Despite the efficiency of mouth rinses with fluoride or chlorohexidine in preventing demineralization, patient compliance has been demonstrated to be very low. ${ }^{23}$ Resin veneer coating method necessitates complicated procedures. ${ }^{21}$ On the other hand, It was claimed that the fluoride-releasing bonding materials had no influence in reducing enamel demineralization due to the low $\mathrm{pH}$ of accumulated plaque adjacent to the brackets. ${ }^{17}$

An adhesive system with fluoride-releasing and antibacterial characteristics, Clearfil Protect Bond (Kuraray Medical, Okayama, Japan) was developed and now on hand..$^{4,25}$ It contains methacryloyloxy dodecylpyridinium bromide (MDPB), an antimicrobial monomer, added to the primer, that has been reported to prevent the growth of bacteria on its surface. ${ }^{26-28}$ Several previous studies confirmed the bacteriostatic effects and an antiplaque characteristic of MDPB.$^{27,29-31}$

It was indicated in many experiments that the SBS of metal brackets bonded with Clearfil Protect Bond is comparable to or even higher than that obtained with Transbond Plus. ${ }^{5,32,33}$

Recently, a fluoride-releasing light-cured resin (Ortho-Coat) has been introduced. It is indicated to coat around the edges of the brackets base and the surrounding enamel, eliminating the accumulation of food and bacteria around and under the brackets and, consequently reducing demineralization of the enamel. ${ }^{34}$ It was concluded that, the application of this protective coat had no negative effect on SBS of metal brackets to enamel. ${ }^{34,35}$ Moreover, this material can be applied in moist condition because it is hydrophilic. ${ }^{34}$

Due to orthodontic adhesives are regularly exposed to thermal alterations in the mouth, it is essential to ascertain if these alterations create stresses in the adhesive that might negatively affect bracket's bond strength to enamel. ${ }^{36,37}$ Therefore, thermocycling should be one of the testing methods of any new adhesive. ${ }^{36}$

Inconsistency among the results of different investigations regarding the SBS values of different 
adhesive systems after thermocycling was indicated by Gale and Darvell ${ }^{38}$ and they related this to the deficiency of standardization among the various thermocycling studies. The chief variations between thermocycling experiments were in the thermal

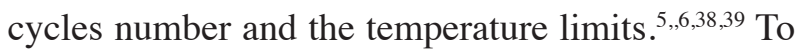
avoid variation among the thermocycling regimens the International Organization for Standardization (ISO) TR 11450 standard indicates a specific thermocycling protocol to enable researchers to interpret and compare results. ${ }^{40}$

Up to date, no data are available for the effect of thermocycling on SBS of orthodontic brackets after application of fluoride-releasing light-cured resin (Ortho-Coat). Therefore, the aim of this in-vitro study was to evaluate the influence of thermocycling following Ortho-Coat application on SBS of brackets bonded with two SEPs systems (Transbond Plus and an antimicrobial, Clearfil Protect Bond).

\section{MATERIALS AND METHODS}

80 upper premolars with intact buccal enamel, caries-free, and no restoration were cleaned and stored in a $0.1 \%$ thymol solution. The teeth were stored for not more than 2 months until used in this study. The teeth were embedded vertically in a self-curing acrylic resin (Rapid Repair,
DeguDent Gmbh, Postafech, Germany) placed in plastic molds. The teeth, then were polished with a fluoride- free pumice and rubber cups for 10 seconds and thoroughly washed with distilled water. The mounted teeth were randomly divided into 4 equal groups.

Stainless steel, standard edgewise, premolar brackets ( American Orthodontics, Sheboygan, WI, USA) were used. The average area of each bracket base was measured to be $11.85 \mathrm{~mm}^{2}$. This value was obtained by randomly measuring 10 bracket bases. The brackets were bonded to the mounted teeth as follows:

Group 1, the buccal surface of each tooth was conditioned with Transbond Plus SEP following the manufacturer's instructions. The primer was applied and rubbed onto the enamel surface for 5 seconds then, lightly dried with an oil-free air stream for 3 seconds to evaporate the solvent. After that, the bracket base was lined with Transbond XT adhesive and seated at the center of the buccal surface. The excess adhesive was removed with a fine scalar followed by light-curing (Cromalux 75, Megaphysik Dental, Germany; output power of $600 \mathrm{~mW} /$ $\mathrm{cm}^{2}$ ) for a total of 30 seconds ( 10 seconds at each of the mesial, distal and occlusal sides). A description of the materials used in this study is shown in Table 1.

TABLE (1) Materials used in the study.

\begin{tabular}{|l|l|l|}
\hline Materials & \multicolumn{1}{|c|}{ Manufacture } & \multicolumn{1}{c|}{ Composition } \\
\hline $\begin{array}{l}\text { Transbond Plu } \\
\text { SEP }\end{array}$ & $\begin{array}{l}\text { 3M Unitek, Monrovia, } \\
\text { Calif, USA }\end{array}$ & $\begin{array}{l}\text { Methacrylated phosphates, a fluoride complex, initiators, and stabilizers in an } \\
\text { aqueous solution. }\end{array}$ \\
\hline Bond SEP & $\begin{array}{l}\text { Kuraray Medical, } \\
\text { Tokyo, Japane }\end{array}$ & $\begin{array}{l}\text { SEP: Methacryloyloxydecyl dihydrogen phosphate(MDP), hydroxyethyl } \\
\text { methacrylate (HEMA), Hydrophobic aliphatic methacrylate, } \\
\text { 12-methacryloyloxydodecyl pyridinium bromide (MDPB) monomer, } \\
\text { Camphorquinone, Initiators, Accelerators; bonding agent: MDP, HEMA, } \\
\text { comonomers, initiators, functionalized sodium fluoride. }\end{array}$ \\
\hline Transbond XT & 3M Unitek, Monrovia, \\
Calif, USA & $\begin{array}{l}\text { Quartz silica, bisphenol A diglycidyl ether dimethacrylate,bisphenol A bis(2- } \\
\text { hydroxyethyl ether) dimethacrylate, dichlorodimethylsilane reaction product } \\
\text { with silica. }\end{array}$ \\
\hline Ortho-Coat & $\begin{array}{l}\text { Pulpdent, Watertown, } \\
\text { Mass, USA }\end{array}$ & \begin{tabular}{l} 
Uncured acrylate resins, silica, amorphous hydrofluoric acid. \\
\hline
\end{tabular} \\
\hline
\end{tabular}


In group 2, the same bonding technique was done as in group 1, however after curing the adhesive, fluoride-releasing light-cured resin (Ortho-Coat) was applied around the bracket base and the encircling enamel surface and light-cured from each of the proximal sides for 20 seconds.

Group 3, the buccal surface of each tooth was conditioned with Clearfil Protect Bond SEP. The primer was used without separately etching the enamel surface. The primer was applied with a sponge applicator onto enamel surfaces in a thin uniform layer, left for 20 seconds and gently airdried for 3 seconds. Then, the bonding agent was applied, distributed evenly with light air stream, and photo-polymerized for 10 seconds. After that, the brackets were bonded using Transbond XT adhesive and photo-polymerized as in group 1 . The manufacture suggested to acid-etch the enamel surface for 10 seconds before applying the primer, but this recommendation was not followed in this study, since several recent studies have shown that this step had no significant positive effect on SBS. . $, 5,9,32,33,41,42^{2}$

In group 4, the same bonding protocol was carried out as in group 3, followed by an application of Ortho-Coat around the bracket and the adjacent enamel surface and light-cured from the mesial and distal sides for 20 seconds.

All specimens were stored in distilled water at $37^{\circ} \mathrm{C}$ for 24 hours. Then half the specimens of each group $(n=10)$ were debonded directly and the other half $(\mathrm{n}=10)$, were subjected to thermocycling and subsequently debonded. Thermocycling was done following the recommendation of the ISO TR $11450 .^{40}$ Specimens were thermocycled for 500 cycles between two thermally controlled water baths maintained at $5^{\circ} \mathrm{C}$ and $55^{\circ} \mathrm{C}$, with a dwell time of 20 seconds in each bath and the transfer time between the two baths was10 seconds.

The brackets were debonded by applying an occluso-gingival load to deliver a shear force at the bracket-tooth interface. This was conducted with the flattened end of a stainless steel blade attached to the crosshead of a universal testing machine (Lloyd LRX; Lloyd Instruments Ltd., Fareham, UK). The brackets were debonded at a crosshead speed of 1 $\mathrm{mm}$ per minute. The maximum load at failure of each bracket was recorded and the SBS (MPa) was calculated by dividing the force at failure $(\mathrm{N})$ by the bracket base area $\left(\mathrm{mm}^{2}\right)$.

After debonding, the enamel surfaces were examined with optical stereomicroscope (Olympus SZ60, Tokyo, Japan) at 10-times magnification to assess the failure pattern depending on the amount of residual adhesive on each tooth. The adhesive remnant index (ARI ${ }^{42}$ was used to count the amount of remaining adhesive by the following scale: 0 , no adhesive remained on the enamel; 1 , less than $50 \%$ of the adhesive remained on the enamel; 2 , more than $50 \%$ of the adhesive remained on the enamel; and 3 , all adhesive remained on the enamel.

\section{Statistical Analysis}

Statistical evaluation was performed using SPSS software program version 16.0 (SPSS Inc., Chicago, IL). The SBS data including mean, standard deviation, and range were calculated for each group. Three-way ANOVA was used to determine the effect of fluoride-releasing resin, thermocycling, and SEP adhesive systems and their interaction on SBS. Kruskal-Wallis test was utilized to verify the ANOVA results. Chi-square test was performed to determine significant differences in ARI scores among groups. P values $<0.05$ are considered to be statistically significant in all tests.

\section{RESULTS}

Descriptive statistics including means, standard deviations, and ranges of SBS data are shown in Table 2. The mean SBS values for all groups are presented graphically in Fig. 1. The 3-way ANOVA results of shear bond strength are presented in Table 3. The application of Ortho-Coat had no significant 
$(P>0.05)$ effect on SBS values of both SEPs, either before or after thermocycling. SBS values of both SEPs were not significantly $(\mathrm{P}>0.05)$ affected by thermocycling whether Ortho-Coat was applied or not. No significant difference $(\mathrm{P}>0.05)$ was noted between the two SEPs, whether the fluoridereleasing resin was applied or not and either before or after thermocycling. No significant correlation ( $\mathrm{P}$ $>0.05$ ) in SBS was found among the three variables (SEP, Ortho-Coat, and thermocycling) or between any two of them. The distribution of the ARI scores are shown in Table 4. The chi-square test of the ARI scores indicated that all groups were not significantly different from each other (chi-square = $6.597, \mathrm{P}=0.949)$. For all groups, the distribution of ARI scores was identical. At least 9 scores of 0 and1 was noted in each group. Moreover, no scores of 3 were observed in all groups, while only 1 score of 2 was found in the groups tested at 24 hours. These observations revealed that the majority of the adhesive remained on the brackets bases in all groups, therefore the predominant failure pattern was at the enamel-adhesive interface.

TABLE (2) Descriptive statistics of SBS values ( MPa) for the two self-etching primer systems.

\begin{tabular}{lcccc}
\hline Group & $n$ & Mean & SD & Rang \\
\hline Transbond Plus & 10 & 11.24 & 0.99 & $9.70-12.76$ \\
Transbond Plus with Ortho-Coat & 10 & 11.57 & 1.19 & $9.56-13.56$ \\
Clearfil Protect Bond & 10 & 11.68 & 1.59 & $10.13-14.23$ \\
Clearfil Protect Bond with Ortho-Coat & 10 & 12.00 & 1.53 & $10.44-14.55$ \\
Transbond Plus and thermocycling & 10 & 11.10 & 1.21 & $9.65-13.45$ \\
Transbond Plus with Ortho-Coat and thermocycling & 10 & 11.78 & 1.45 & $9.61-14.66$ \\
Clearfil Protect Bond and thermocycling & 10 & 11.63 & 1.69 & $9.46-14.43$ \\
Clearfil Protect Bond with Ortho-Coat and thermocycling & 10 & 11.93 & 1.74 & $9.41-14.65$ \\
\hline
\end{tabular}

Main effect of fluoride resin was not significant $(P=0.209)$, Main effect of thermocycling was not significant $(P=0.966)$, Main effect of SEP type was not significant $(P=0.237)$, Interactions among the 3 variables were not significant $(P=0.776)$.

TABLE (3) Three-way ANOVA of SBS for the two self-etching primer systems.

\begin{tabular}{lccccc}
\hline Source & Sum of Square & $d f$ & Mean Square & $F$ & $P$-value \\
\hline Corrected Models & $6.881^{\mathrm{a}}$ & 7 & 0.983 & 0.470 & 0.853 \\
Intercept & 10796.143 & 1 & 10796.143 & 5161.144 & 0.000 \\
SEP system & 2.968 & 1 & 2.968 & 1.419 & 0.237 \\
Ortho-Coat & 3.358 & 1 & 3.358 & 1.605 & 0.209 \\
Thermocycling & 0.004 & 1 & 0.004 & 0.002 & 0.966 \\
SEP * Ortho-Coat & 0.191 & 1 & 0.191 & 0.091 & 0.763 \\
SEP * Thermocycling & 0.041 & 1 & 0.041 & 0.020 & 0.889 \\
Ortho-Coat * Thermocycling & 0.149 & 1 & 0.149 & 0.071 & 0.790 \\
SEP * Ortho-Coat * Thermocycling & 0.170 & 1 & 0.170 & 0.081 & 0.776 \\
Error & 150.610 & 72 & 2.092 & & \\
Total & 10953.634 & 80 & & & \\
Corrected Total & 157.492 & 79 & & & \\
\hline
\end{tabular}

a. $R$ Squared $=0.044$ (Adjusted $R$ Squared $=-0.049)$ 
TABLE (4) Frequency distribution (and percentages) of the ARI Scores

\begin{tabular}{lccccc}
\hline Group & $\boldsymbol{n}$ & 0 & 1 & 2 & 3 \\
\hline Transbond Plus & 10 & $5(50 \%)$ & $4(40 \%)$ & $1(10 \%)$ & $0(0.0 \%)$ \\
Transbond Plus with Ortho-Coat & 10 & $5(50 \%)$ & $4(40 \%)$ & $1(10 \%)$ & $0(0.0 \%)$ \\
Clearfil Protect Bond & 10 & $5(50 \%)$ & $4(40 \%)$ & $1(10 \%)$ & $0(0.0 \%)$ \\
Clearfil Protect Bond with Ortho-Coat & 10 & $6(60 \%)$ & $3(30 \%)$ & $1(10 \%)$ & $0(0.0 \%)$ \\
Transbond Plus and thermocycling & 10 & $7(70 \%)$ & $3(30 \%)$ & $0(0.0 \%)$ & $0(0.0 \%)$ \\
Transbond Plus with Ortho-Coat and thermocycling & 10 & $7(70 \%)$ & $3(30 \%)$ & $0(0.0 \%)$ & $0(0.0 \%)$ \\
Clearfil Protect Bond and thermocycling & 10 & $7(70 \%)$ & $3(30 \%)$ & $0(0.0 \%)$ & $0(0.0 \%)$ \\
Clearfil Protect Bond with Ortho-Coat and thermocycling & 10 & $8(80 \%)$ & $2(20 \%)$ & $0(0.0 \%)$ & $0(0.0 \%)$ \\
\hline
\end{tabular}

Chi-square $=6.59, d f=14, P=0.949$

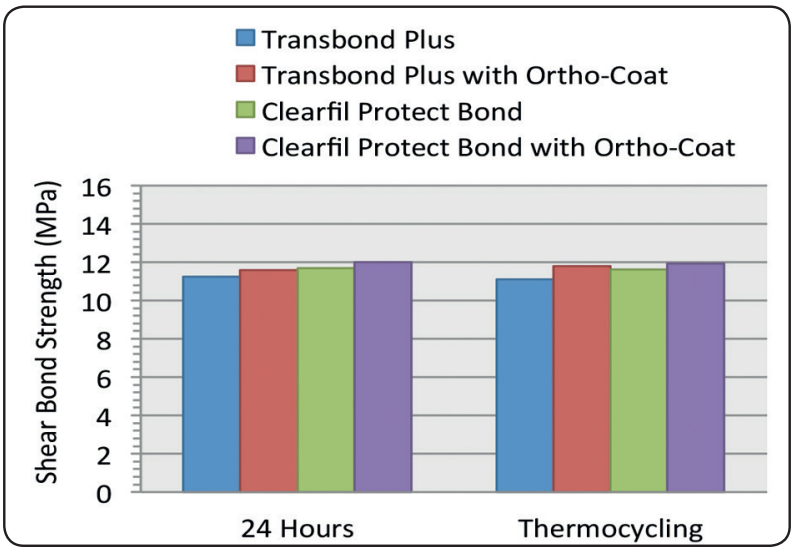

Fig. (1) Chart of mean SBS values for all groups.

\section{DISCUSSION}

During fixed orthodontic treatments, plaque and food residues collect easily under brackets, where it is greatly difficult to clean, even in patients with good oral hygiene, which may result in caries, enamel demineralization, or staining. Therefore, preventive procedures and/or materials to protect the areas beneath and surrounding the brackets would be extremely helpful. ${ }^{34}$

Under the conditions of this study, SBS of both SEPs was not affected with the application of Ortho-Coat either before or after thermocycling. The present results before thermocycling (24 h) are in agreement with the results of Tuncer et al. ${ }^{34}$ They concluded that the application of fluoride-releasing resin does not reveal a detrimental effect on SBS. However, the results of the present study regarding Transpond Plus after thermocycling are different than that obtained in a previous study, ${ }^{35}$ where the SBS was increased after application of Ortho-Coat. In that study, the SEP used was Transbond XT and at the same time the specimens were stored in distilled water for 4 weeks before thermocycling, which might explain the difference in results. It has been stated that, the fluoride-releasing light-cured resin, Ortho-Coat, has a significant role in reducing enamel demineralization and microleakage under orthodontic brackets. ${ }^{34,35}$ Application of topical fluoride agents to tooth surface have also been suggested as effective mechanism in preventing dental caries and control the formation of enamel lesions during fixed orthodontic treatment.$^{43}$ Fluoride ions promote the formation of fluorohydroxyapatite, which is less soluble in the acidic challenge of plaque than hydroxyapatite, ${ }^{44}$ but fluoroapatite was suggested to influence bond strength. ${ }^{45}$ However, another studies ${ }^{46,47}$ proved that brackets-enamel bond strength was not harmfully affected with the fluoride application, which are in parallel with the findings of this study.

The SBS of the brackets bonded with either of two SEPs used in this study was not significantly affected after 500 thermocycles either with or without Ortho-Coat application. These results are consistent with the results of Gasgoos and Ra'ed, ${ }^{48}$ 
who demonstrated that there was no significant decrease in SBS of brackets bonded with Transbond Plus and Clearfil Protect Bond SEPs after 500 thermal cycles. These result are, also verified by Saito et al ${ }^{6}$ who reported that the SBS of orthodontic brackets bonded with Clearfil Protect Bond SEP was not affected after thermocycling. Moreover, SBS of metal brackets bonded with Transbond Plus SEP after three different storage conditions (24h.,2 years, and thermocycling (6000 cycles) was determined by Yuasa et al, ${ }^{49}$ and the results showed that there was no significant difference in SBS values among the three storage conditions. On the other hand, in the study of Elecdag-Turk, ${ }^{39}$ a significant reduction in SBS of Transbond Plus SEP was found after 2000 and 5000 thermocycles. However, comparing the SBS results from different experiments is not practical and unaccurate due to the variation in the materials and methods; including thermocycling protocols, storage conditions, methods of primer application, tooth type, , debonding technique, and interpretation of the results. ${ }^{50}$ Due to the deficiency of standardization among the various thermocycling studies, ${ }^{38}$ the protocol of the International Organization for Standardization, ${ }^{40}$ for conducting thermocycling test were followed in this study.

Recently, Procedures and techniques of bonding orthodontic brackets with the aim of conserving the tooth structure and saving chair-time are replacing the conventional method. ${ }^{31}$ The conventional method require the use of $37 \%$ phosphoric acid for etching the enamel surface, but bonding to the etched enamel has many disadvantages such as decalcification under and adjacent to the bracket as well as surface enamel loss and weakening of the subsurface enamel that might cause enamel fracture during debonding. ${ }^{7}$ SEP systems has become popular and accepted technique for brackets bonding due to their gentle etch pattern, simplified procedure, and time-saving. ${ }^{4,5,13,31,51}$ It was proposed that bond strengths of 6 to $9 \mathrm{MPa}$ are enough and acceptable for clinical orthodontic brackets bonding. ${ }^{52,53}$ In the literature, self-etching adhesive systems used for bonding orthodontic brackets showed significantly variable SBS values, but the clinically acceptable bond strength of 6 to 9 was succeeded in most of these studies. . $^{4,24,51}$

In the present study, no significant difference in SBS was found between the 2 SEPs (Transbond Plus and Clearfil Protect bond) used, whether OrthoCoat was applied or not and either before or after themocycling. At the same time, the SBS values obtained with the 2 SEPs in all situations were higher than those minimally required clinically in orthodontic treatment. In an agreement with this study, Bulut et al. ${ }^{24}$ and Scougall-Vilchis et al..$^{54}$ compared the SBS of brackets bonded with the same 2 SEPs used in this study and found that bond strengths of the two SEPs were also comparable and clinically acceptable. On contrary, in another investigation, ${ }^{23}$ brackets bonded with Clearfil Protect Bond exhibited higher bond strength than with Transbond Plus, which disagree with the present results. This difference might be related to the enamel in that study was acid-etched for 10 seconds before applying Clearfil Protect Bond as recommended by the manufacturer, while in this study the Clearfil Protect Bond was applied into intact enamel. In the present study, Clearfil Protect Bond was applied into intact enamel because it has been shown in several previous studies ${ }^{5,32,33,41}$ that the etching step might not be necessary, because the obtained SBS value was acceptable without this step and comparable with the recommended bond strength in the literature. Also, acid etching complicates the clinical procedure and increases chair time. ${ }^{34}$ Clearfil Protect Bond contains MDPB monomer included in its primer that has prevent the growth of bacteria on its surface ${ }^{26-28}$ In previous investigations, ${ }^{32,33}$ it was noted that the inclusion of MDPB in the primer had no adverse effect on the SBS of an orthodontic bracket to enamel. However in another study, ${ }^{31}$ a higher SBS was achieved by adding $1 \%$ to $2 \%$ MDPB monomer to the primer. In the present study, Clearfil Protect Bond exhibited an adequate SBS, which was comparable to the results of previous studies, ${ }^{24,34,51}$ and it might recommended for patients with poor oral hygien. ${ }^{54}$ 
The adhesive remnant index scores in this study indicated that brackets bonded with either SEP adhesive system, either with or without OrthoCoat and either before or after thermocycling, showed the same range of bond failure pattern. The predominant mode of failure was at the enameladhesive interface in all groups, based on most of the adhesive remained on the bracket bases. These findings, for groups tested at $24 \mathrm{~h}$, are consistent with that of Tuncer et al. ${ }^{34}$ No scores of 3 were observed in all groups, while only 1 score of 2 was found in the groups tested at 24 hours. There were no significant differences in the distribution of ARI scores in all groups. These outcomes pointed out that Ortho-Coat or/and thermocycling had no significant effect on ARI scores of the two SEPs. Bracket failure pattern at enamel-adhesive interface has the advantage of less residual adhesive left on the enamel that can be cleaned easily and faster, but enamel loss can occur with this failure mode. However, bracket failure at bracketadhesive interface has the advantage of leaving the enamel surface intact, but more time is needed for removal of residual adhesive with the probability of harming the enamel surface during cleaning. ${ }^{37}$ Conflicting results were reported in many studies about the amount of residual adhesive remained on the enamel using self-etching primers for bonding orthodontic brackets. ${ }^{2,55,56}$ These contradictions might be contributed to differences in bracket-base surface areas, storage conditions, variable bonding protocols, or the classification system of ARI. ${ }^{34}$

\section{CONCLUSIONS}

1. SBS of orthodontic brackets bonded with two self-etching primer systems was not negatively affected with the application of fluoridereleasing resin (Ortho-Coat).

2. Thermocycling had no effect on SBS of the two self-etching primer systems either with or without fluoride resin application.

3. Both SEP systems achieved comparable SBS values in any application condition.
4. ARI scores indicated that the predominant mode of bracket failure was at the enamel-adhesive resin interface in all groups.

5. No significant correlation was found between any of the three variables.

\section{ACKNOWLEDGMENT}

The author would like to thank Dr. Ahmed Yosry, former Lecturer of Orthodontics, Faculty of Dentistry, Tanta University, Egypt, for his help and advice.

\section{REFERENCES}

1. Pandis N, Polychronopoulou A, Eliades T: Failure rate of self- ligating and edgewise brackets bonded with conventional acid etching and a self-etching primer: a prospective in vivo study. Angle Orthod 2006;76:119-22.

2. Bishara SE, VonWald L, Laffoon JF, Warren JJ: Effect of a self-etch primer/adhesive on the shear bond strength of orthodontic brackets. Am J Orthod Dentofacial Orthop 2001;119:621-624.

3. Carestensen W. The effects of different phosphoric acid consentrations on surface enamem. Angle Orthod 1992;62:51-58.

4. Cacciafesta V, Sfondrini MF, De Angelis M, Scribante A,Klersy C: Effect of water and saliva contamination on shear bond strength of brackets bonded with conventional, hydrophilic, and self-etching primers. Am J Orthod Dentofacial Orthop 2003;123:633-640.

5. Eminkahyagil N, Korkmaz Y, Gokalp S, Baseren M: Shear bond strength of orthodontic brackets with newly developed antibacterial self-etch adhesive. Angle Orthod 2005;75:843-848

6. Saito K, Sirirungrojying S, Meguro D, Hayakawa T, Kasai $\mathrm{K}$ : Bonding durability of using self-etching primer with 4- META/ MMA-TBB resin cement to bond orthodontic brackets. Angle Orthod. 2005;75:260-265.

7. Kim MJ, Lim BS, Chang WG, Lee YK, Rhee SH, Yang HC: Phosphoric acid incorporated with acidulated phosphate fluoride gel etchant effects on bracket bonding. Angle Orthod 2005;75:678-684.

8. Bishara SE, Ajlouni R, Laffoon JF, Warren JJ: Comparison of shear bond strength of two self-etch primer/adhesive systems. Angle Orthod 2006;76:123-126. 
9. Grubisa HS, Heo G, Raboud D, Glover KE, Major PW: An evaluation and comparison of orthodontic bracket bond strengths achieved with self-etching primer. Am J Orthod Dentofacial Orthop 2004;126:213-219.

10. Vicente A, Bravo LA, Romero M. Influence of a nonrinse conditioner on the bond strength of brackets bonded with a resin adhesive system. Angle Orthod 2005;75:400-405.

11. Arnold RW, Combe EC, Warford JH Jr: Bonding of stainless steel brackets to enamel with a new self-etching primer. Am J Orthod Dentofacial Orthop 2002;122:274-276.

12. Turk T, Elekdag-Turk S, Isci D. Effects of self-etching primer on shear bond strength of orthodontic brackets at different debond times. Angle Orthod 2007;77:108-112.

13. Paschos E, Westphal JO, Ilie N, Huth KC, Hickel R, Rudzki- Janson I: Artificial saliva contamination effects on bond strength of self-etching primers. Angle Orthod 2008;78:716-21.

14. Polat O, Uysal T, Karaman AI. Effects of a cllorohexidune varnish on shear bond strength in indirect bonding. Angle Orthod 2005; 75:1036-1040.

15. Ogaard B, Larsson E, Henriksson T, Birkhed D, Bishsara SE. Effects of combined application of antimicrobial and fluoride varnishes in orthodontic patients. Am J Orthod Dentofacial Orthop 2001;120:28-35.

16. Gorelick L, Geiger AM, Gwinnett AJ: Incidence of white spot formation after bonding and banding. Am J Orthod 1982;81:93-8.

17. Derks A, Katsaros C, Frencken JE, van't Hof MA, Kuijpers- Jagtman AM: Caries-inhibiting effect of preventive measures during orthodontic treatment with fixed appliances. A systematic review. Caries Res 2004;38:413-420.

18. Stecksen-Blicks C, Renfors G, Oscarson ND, Bergstrand F, Twetman S: Caries-preventive effectiveness of a fluoride varnish: a randomized controlled trial in adolescents with fixed orthodontic appliances. Caries Res 2007;41:455-459.

19. Wenderoth CJ, Weinstein M, Borislow AJ: Effectiveness of a fluoride-releasing sealant in reducing decalcification during orthodontic treatment. Am J Orthod Dentofacial Orthop 1999;116:629-634.

20. Gillgrass TJ, Greanor SL, Foye RH, Millet DT. Varnish or polymeric coating for the prevetion of demineralization. An ex vivo study. J Orthod 2001;28:291-295.
21. Miwa H, Miyazawa K, Goto S, Komdo T, hasegawa A. A resin veneer for enamel protection during orthodontic treatment. Eur J Orthod 2001;23:759-767.

22. Banks PA, Chadwick SM, Asher-McDade C, Wright JL: Fluoride-releasing elastomerics - a prospective controlled clinical trial. Eur J Orthod 2000;22:401-407.

23. Geiger AM, Gorelick L, Gwinnett AJ, Benson BJ: Reducing white spot lesions in orthodontic populations with fluoride rinsing. Am J Orthod Dentofacial Orthop 1992;101:403-407.

24. Bulut H, Turkun M, Turkun LS, Isiksal E: Evaluation of the shear bond strength of 3 curing bracket bonding systems combined with an antibacterial adhesive. Am J Orthod Dentofacial Orthop 2007;132:77-83.

25. Kawashima M, Nakatsuka K, Okada K, Yamauchi J. Characteristics o a new antibacterial and fluoride releasing bonding system [abstract 1850]. IADR 2002.

26. Imazato S, Kuramoto A, Takahashi Y, Ebisu S, Peters MC: In vitro antibacterial effects of the dentin primer of Clearfil Protect Bond. Dent Mater 2006;22:527-532.

27. Imazato S, Torii Y, Takatsuka T, Inoue K, Ebi N, Ebisu $\mathrm{S}$ : Bactericidal effect of dentin primer containing antibacterial monomer methacryloyloxydodecylpyridinium bromide (MDPB) against bacteria in human carious dentin. $\mathrm{J}$ Oral Rehabil 2001;28:314-9.

28. Paschos E, Kurochkina N, Huth KC, Hansson CS, RudxziJanson I. Failure rate of brackets bonded with antimicrobial and fluoride releasing, self-etching and the effect on prevention of enamel demineralization. Amer J Orthod Dentofacial Orthoped 2009;135;613-620.

29. Ebi N, Imazato S, Noiri Y, Ebisu S: Inhibitory effects of resin composite containing bactericide-immobilized filler on plaque accumulation. Dent Mater 2001;17:485-491.

30. Imazato S, Ebi N, Tarumi H, Russell RR Kaneko T, Ebisu S. Bactericidal activity and cytotoxicity of antibacterial monomer MDPB. Biomaterials 1999;20:899-903.

31. Imazato S, Ebi N, Takahashi Y, Kaneko T, Ebisu S, Russell RR: Antibacterial activity of bactericide-immobilized filler for resin- based restoratives. Biomaterials 2003;24:3605-3609.

32. Arhun N, Arman A, Sesen C, Karabulut E, Korkmaz Y,Gokalp S: Shear bond strength of Orthodontic brackets with 3 self-etch adhesives. Am J Orthod Dentofacial Orthop 2006;129:547-550. 
33. Bishara SE, Soliman M, Laffoon J, Warren JJ: Effect of antimicrobial monomer-containing adhesive on shear bond strength of orthodontic brackets. Angle Orthod 2005;75:397-399.

34. Tuncer C, Tuncer BB, Ulusoy C: Effect of fluoride-releasing light-cured resin on shear bond strength of orthodontic brackets. Am J Orthod Dentofacial Orthop 2009; 135: 14.e1-14.e6.

35. Abdelnaby YL and Al-Wakeel EE. Influence of modifying the resin coat application proyocol on bond strength amd microleakage of metal orthodontic brackets. Angle Orthod 2010;80:378-384.

36. Bishara SE, Ajlouni R, Laffoon JF: Effect of thermocycling on the shear bond strength of a cyanoacrylate orthodontic adhesive. Am J Orthod Dentofacial Orthop. 2003;123:21-24.

37. Bishara SE, Ostby AW, Laffoon JF, Warren J: Shear bond strength comparison of two adhesive systems following thermocycling. Angle Orthod. 2007;77:337-341.

38. Gale MS, Darvell BW: Thermal cycling procedures for laboratory testing of dental restorations. J Dent. 1999;27:89-99.

39. Elekdag-Turk S, Turk T, Isci D, Ozkalayci N: Thermocycling effects on shear bond strength of a self-etching primer. Angle Orthod 2008; 78: 351-356.

40. International Organization for Standardization. 1994. Dental Materials-Guidance on testing on Adhesion to Tooth Structure. Geneva, Switzerland ISO TR 11405.

41. Korbmacher HM, Huck L, Kahl-Nieke B: Fluoride-releasing adhesive and antimicrobial self-etching primer effects on shear bond strength of orthodontic brackets. Angle Orthod 2006; 76:845-850.

42. Bishara SE, Oonsombat C, Ajlouni R, Laffoon JF: Comparison of the shear bond strength of 2 self-etch primer/ adhesive systems. Am J Orthod Dentofacial Orthop 2004;125:348-350.

43. Donly KJ, Sasa IS. Potential remineralization of post orthodontic demineralized enamel and the use of enamel microabrasion and bleaching for esthetics. Semin Orthod 2008;14:220-225.

44. Oztoprak MO, Isik F, Sayinus K, Arun t, Aydemir B. Effect of blood and saliva contamination on shear bond strength of brackets bonded with 4 adhesives, Am J Orthod Dentofacial Orthop 2007;131:238-242.
45. Aasenden R, DePaola PF, Brudevold F: Effects of daily rinsing and ingestion of fluoride solutions upon dental caries and enamel fluoride. Arch Oral Biol 1972;17:17051714.

46. Wang WN, Sheen DH: The effect of pretreatment with fluoride on the tensile strength of orthodontic bonding. Angle Orthod 1991;61:31-34.

47. Bishara SE, Chan D, Abadir EA: The effect on the bonding strength of orthodontic brackets of fluoride application after etching. Am J Orthod Dentofacial Orthop 1989;95:259-260.

48. Gasgoos SS, Sa'id RJ: The effect of thermocycling on shear bond strength of two types of self- etch primers. AlRafidain Dent J 2009; 9: 246-253.

49. Yuasa T, Lijima M, Ito S, Muguruma T, Saito T, mizoguchi I: Effects of long-term storage and thermocycling on bond strength of two self-etching primer adhesive systems. Eur J Orthod 2010; 32:285-290.

50. Fox NA, McCabe JF, Buckley JG: A critique of bond strength testing in orthodontics. 1994;21:33-43.

51. Scougall-vilchis RJ, Yamamoto S, Kitia N, Yamamoto K. Shear bond strength of orthodontic brackets with different self-etching adhesives. Am J Orthod Dentofacial Orthop 2009;136:425-430.

52. Reynolds IR. A review of direct orthodontic bonding. Br Dent J 1975;2:171-178.

53. Powers JM, Messersmith ML. Enamel etching and bond strength. In: Brantley W A, Eliades T, editors. Orthodontic materials: scientific and clinical aspects. New York: Thieme; 2001. P. 107-112.

54. Scougall-vilchis RJ, Ohashi S Yamamoto K. Effects of 6 self-etching primers on shear bond strength of orthodontic brackets. Am J Orthod Dentofacial Orthop 2009;135:424. e1-424.e7.

55. Romano FL, Tavares SW, Nouer DF, Consani S, Borges de Araujo Magnani MB: Shear bond strength of metallic orthodon- tic brackets bonded to enamel prepared with self-etching primer. Angle Orthod 2005;75:849-853.

56. Bishara SE, Gordan VV, VonWald L, Jacobsen JR: Shear bond strength of composite, glass ionomer and an acidic primer adhesive system. Am J Orthod Dentofacial Orthop 1999;115:24-28 